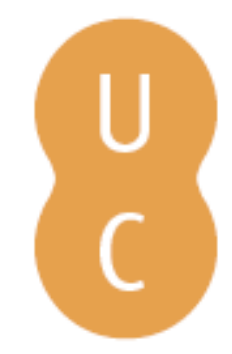

\title{
pompalina
}

\section{Desafios colocados à cartografia das áreas de susceptibilidade de ravinamento a partir de estudos no Centro de Portugal}

\begin{tabular}{ll} 
Autor(es): & $\begin{array}{l}\text { Martins, Bruno Manuel; Lourenço, Luciano Fernandes; Rocha, Raphael } \\
\text { Costa Cristovam da }\end{array}$ \\
Publicado por: & $\begin{array}{l}\text { Imprensa da Universidade de Coimbra; RISCOS - Associação } \\
\text { Portuguesa de Riscos, Prevenção e Segurança }\end{array}$ \\
$\begin{array}{ll}\text { URL } \\
\text { persistente: }\end{array}$ & URI:http://hdl.handle.net/10316.2/34823 \\
DOI: & DOI:http://dx.doi.org/10.14195/978-989-96253-3-4_32 \\
Accessed : & 26-Apr-2023 13:04:47 \\
\hline
\end{tabular}

A navegação consulta e descarregamento dos títulos inseridos nas Bibliotecas Digitais UC Digitalis, UC Pombalina e UC Impactum, pressupõem a aceitação plena e sem reservas dos Termos e Condições de Uso destas Bibliotecas Digitais, disponíveis em https://digitalis.uc.pt/pt-pt/termos.

Conforme exposto nos referidos Termos e Condições de Uso, o descarregamento de títulos de acesso restrito requer uma licença válida de autorização devendo o utilizador aceder ao(s) documento(s) a partir de um endereço de IP da instituição detentora da supramencionada licença.

Ao utilizador é apenas permitido o descarregamento para uso pessoal, pelo que o emprego do(s) título(s) descarregado(s) para outro fim, designadamente comercial, carece de autorização do respetivo autor ou editor da obra.

Na medida em que todas as obras da UC Digitalis se encontram protegidas pelo Código do Direito de Autor e Direitos Conexos e demais legislação aplicável, toda a cópia, parcial ou total, deste documento, nos casos em que é legalmente admitida, deverá conter ou fazer-se acompanhar por este aviso.

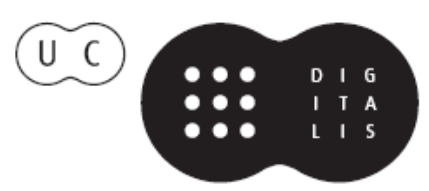



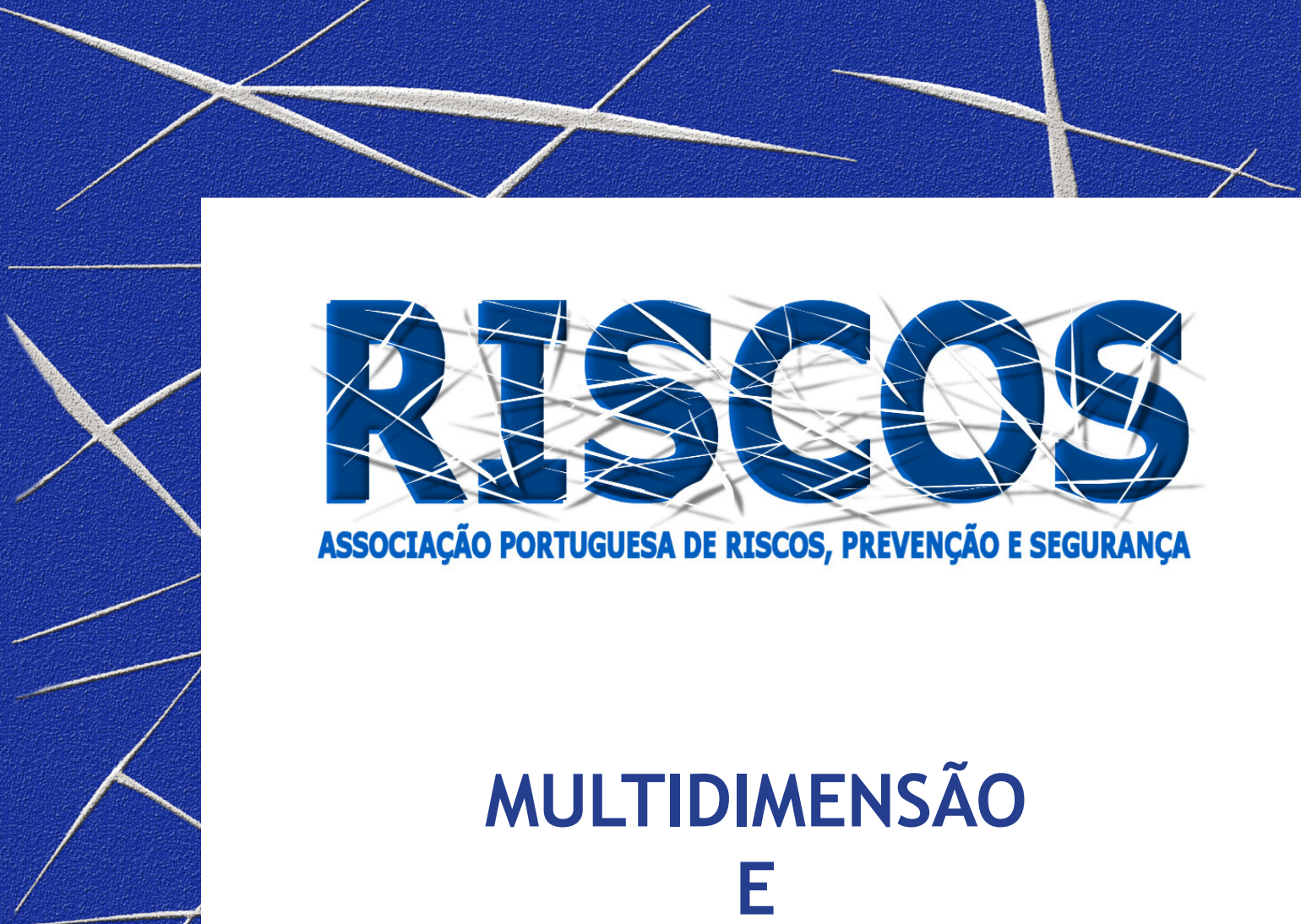

ASSOCIAÇÃO PORTUGUESA DE RISCOS, PREVENCCÃO E SEGURANÇA

MULTIDIMENSÃO

E
TERRITÓRIOS DE RISCO

III Congresso Internacional

I Simpósio Ibero-Americano

VIII Encontro Nacional de Riscos

Guimarães

2014 


\title{
DESAFIOS COLOCADOS À CARTOGRAFIA DAS ÁREAS DE SUSCEPTIBILIDADE DE RAVINAMENTO A PARTIR DE ESTUDOS NO CENTRO DE PORTUGAL
}

\author{
Bruno Manuel Martins \\ Departamento de Geografia e CEGOT, Faculdade de Letras, Universidade de Coimbra \\ bruno.martins@uc.pt \\ Luciano Fernandes Lourenço \\ Departamento de Geografia e CEGOT, Faculdade de Letras, Universidade de Coimbra \\ luciano@uc.pt \\ Raphael Costa Cristovam da Rocha \\ Departamento de Geografia, Faculdade de Letras da Universidade de Coimbra \\ raphaelrocha.br@gmail.com
}

\begin{abstract}
RESUMO
Os ravinamentos são formas de erosão resultantes de processos geomorfológicos que podem contribuir para a perda de solo. De per si, nem sempre afetam áreas de interesse económico. No entanto, mesmo que a perda de solo e de produtividade de um campo agrícola por ravinamento, no seu conjunto, seja considerada de menor importância, os efeitos secundários, podem traduzir-se em grandes prejuízos. A importância da cartografia deste tipo de processo geomorfológico, que se traduz numa manifestação de risco geomorfológico, é proporcional à dificuldade da sua execução. 0 estudo da ravina do Corgo pretende analisar a multiplicidade de factores que estão na sua génese, bem como a arduidade de os representar espacialmente.
\end{abstract}

Palavras-chave: Ravinamentos; riscos geomorfológicos; cartografia; Corgo.

\section{Introdução}

A presença de ravinas é particularmente comum em áreas de montanha. Em muitas regiões, participa de forma muito influente como processo erosivo, contribuindo para a degradação e perda de solo, bem como fonte de material para sedimentação. Vários estudo têm demonstrado que a produção de sedimentos associado aos ravinamentos deverá implicar uma maior atenção (Kheir et al. 2007), em especial nas regiões semi-húmidas e semiáridas dos países mediterrâneos (Rebelo 2010; Tsimi et al. 2012). Os processos de erosão hídrica associados aos processos de ravinamentos traduzem-se em prejuízos agrícolas, perda da capacidade produtiva dos solos e de perda de qualidade da água, em especial nos rios, lagos e reservatórios (Martinez-Casasnovas, et al. 2003). A formação de ravinas está associada às características climáticas e está relacionada a fatores físicos como o declive, forma e tamanho da bacia hidrográfica, propriedades físicas, químicas e mineralógicas dos solos ou a presença de material pouco coeso a regularizar as vertentes, como mantos de alteração ou depósitos de vertente (Martins et al. 2014). Os factores antropogénicos são fundamentais na instalação e evolução das ravinas e na capacidade erosiva das mesmas, através da desflorestação, incêndios, lavra, pastagens, remoção da vegetação remanescente ou construção de estradas. Na maioria das vezes, promovem a concentração da escorrência e a diminuição da infiltração. Neste artigo é objetivo identificar os fatores mais importantes na formação e desenvolvimento das ravinas e a sua arduidade de os representar espacialmente, a partir do caso da ravina do Corgo, situada frente às Caldas de São Paulo, no vale do rio Alva. Para além da análise dos aspectos físicos, é também analisada a participação do ser humano, como fator ativo no desenvolvimento deste tipo de processo, em especial, através dos incêndios florestais. 


\section{Processos fundamentais na génese e evolução das ravinas}

Do ponto de vista teórico poder-se-ão distinguir dois tipos de erosão: (i) erosão "natural”, sem intervenção antrópica; (ii) erosão acelerada por intervenção antrópica. Esta última traduz-se por uma rápida remoção do solo, em resultado da ausência de vegetação, expondo-o diretamente à ação erosiva, especialmente hídrica e eólica, com consequências no aumento da capacidade e competência erosiva. A formação de ravinamentos associa-se, na grande maioria das vezes, a este último tipo de erosão. Sem proteção pela presença de vegetação, o processo de ravinamento inicia-se com a precipitação, em particular, com o efeito do splash sobre o solo. O impacto da gota de chuva sobre a parte superior do solo desagrega-o e as partículas são lançadas em todas as direções induzindo uma poro-pressão positiva no solo e formação de ponds (DePloey, 1983). Este fenómeno é especialmente importante quando se trata de material pouco coeso. À medida que a dimensão dos ponds aumenta, rompem-se e ligam-se entre si através de knickpoints, gerando um processo de escorrência que conduzirá à formação de pequenos canais que poderão evoluir para ravinas (RillGrow) (figura 1). Este processo desenvolve-se geralmente nos sectores da vertente mais próximos da base (Favis-Morlock, 1996) à medida que a área fornecedora de água aumenta de montante para jusante. 0 processo de iniciação de uma ravina implica necessariamente que haja uma certa concentração do fluxo de água e que sejam rompidos certos limites em termos de condições hidráulicas. A passagem de sulcos para ravinas está em parte condicionado pelo declive que determina as condições de energia potencial e de energia cinética de uma vertente. Para que se formem ravinas é necessário que haja valores de declive superiores a 2 ou 3 graus (DePloey, 1983). 0 aumento de declive influi na velocidade do fluxo de água de escorrência, factor fundamental na formação e no desenvolvimento de ravinas. Simulações em laboratório sugerem velocidades superiores a $3,2 \mathrm{~cm} / \mathrm{s}$ para a formação de ravinas (Slatery e Bryan, 1992). Assim, a presença de sulcos poderá ser um indicador de erosão e de uma hipotética evolução para ravinas. A forma e tamanho da bacia hidrográfica é também um fator que vai ter influência na susceptibilidade de uma vertente ao processo de ravinamento, por influir no tempo de concentração e no pico de escorrência. Bacias mais largas apresentam maior susceptibilidade ao aumentarem o rácio de escorrência por tempo. Tal situação sugere que, embora o declive seja um dos factores mais importantes no desenvolvimento das ravinas, excetuando os declives inferiores a 2 graus ou os próximos da verticalidade, a presença de ravinas pode ocorrer em qualquer sector da vertente. 


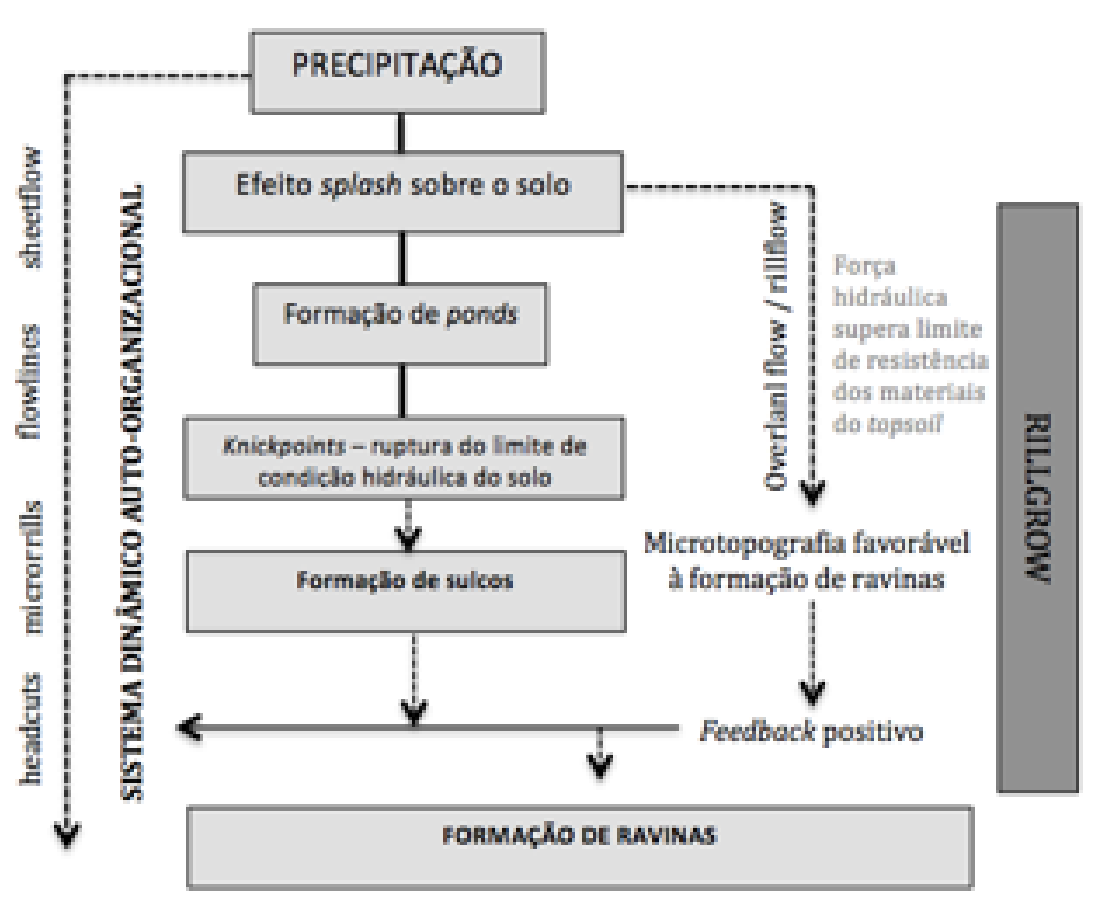

Figura 1 - Esquema simplificado de formação de ravinas, adaptado de Slatery e Bryan (1992) e DePloey (1983).

\section{O exemplo da ravina do Corgo}

A ravina desenvolve-se numa vertente de forte declive, superior a 30 graus, numa área de contacto entre rochas granitóides e metassedimentares. A presença de inúmeras falhas terá contribuído para a existência de um manto de alteração profundo, funcionando como goteira ao permitir uma maior infiltração da água em profundidade. A presença do manto de alteração é fundamental para a evolução da ravina em profundidade. Trata-se de material constituído fundamentalmente por areias grossas em que a classe granulométrica mais abundante são as areias com $2 \mathrm{~mm}$ de diâmetro. Contrariamente a fração silto-argilosa é escassa, gerando uma marcada assimetria entre a quantidade de partículas grosseiras e finas (figura 2). As características arenosas do sedimento onde se desenvolve a ravina confirma a ideia de que as ravinas que se desenvolvem sobre este tipo de material tendem a ser mais profundas e estreitas (foto 1) em contraste com material mais rico em argila, onde tendem a ser mais largas, mais curtas e menos profundas (Bowyer-Bower \& Bryan, 1986). A elevada capacidade de absorver grandes quantitativos de água permite que a meteorização vá progredindo de forma mais intensa e profunda. No caso da vertente da ravina do Corgo, a espessura dos mantos ultrapassa em inúmeros sectores da vertente 5 metros de profundidade e dita o perfil longitudinal da ravina. 


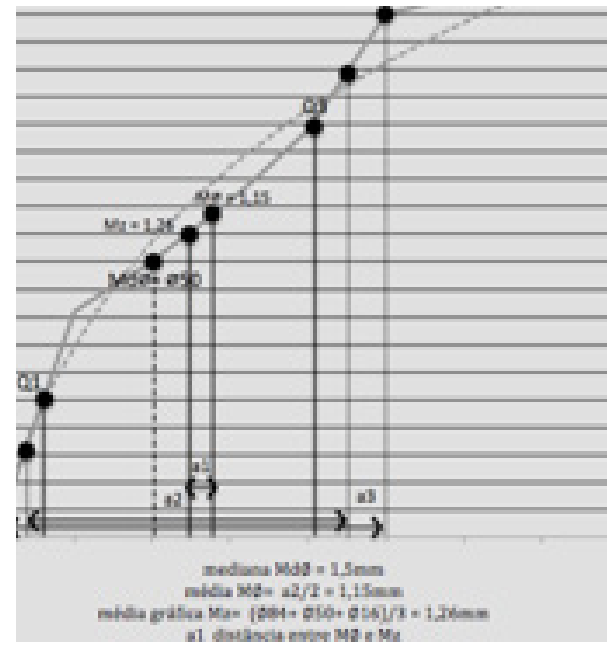

Figura 2 - Ilustração gráfica de algumas medidas descritivas da curva granulométrica;

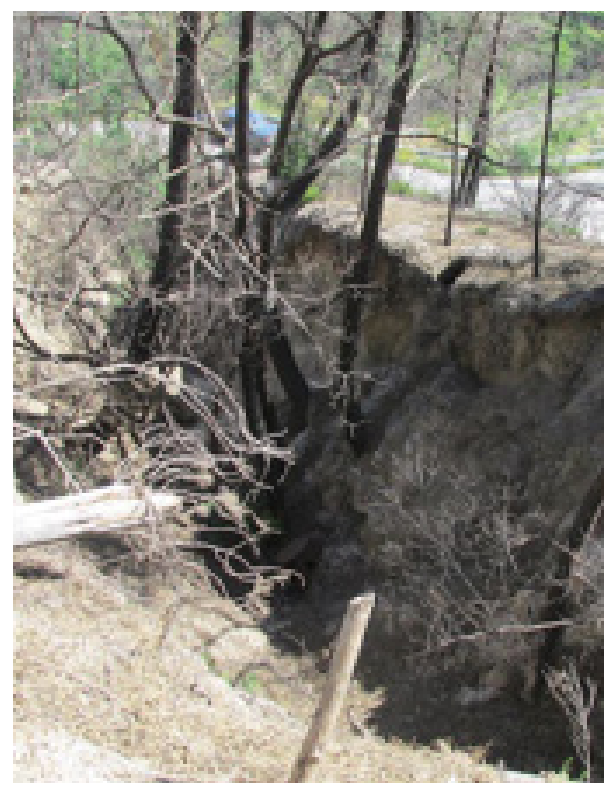

Foto 1 - Secção intermédia da ravina do Corgo. 


\section{A cartografia das áreas incendiadas}

A cartografia das áreas incendiadas tem vindo a assumir grande interesse nos últimos anos, uma vez que se trata de áreas de maior susceptibilidade a processos erosivos (Lourenço e Nunes, 2014), em particular, à formação de ravinas. A sua inclusão na cartografia de susceptibilidade é consequentemente muito importante. A ravina do Corgo desenvolve-se numa vertente que foi sujeita a repetidos episódios de incêndios, mais ou menos intensos, ao longo dos últimos anos. Este terá sido um dos fatores mais importantes na sua génese. Para a definição das áreas incendiadas e a sua intensidade foi utilizado o índice NBR (Normalized Burnt Ratio) obtido a partir das imagens de satélite LANDSAT 8 trabalhado a partir da função Raster Calculator do software QuantumGIS 2.2 Valmiera. Este índice, para além da identificação das áreas incendiadas, permite identificar ainda os diferentes níveis de danos causados pelo fogo na vegetação (Garcia \& Chuvieco, 2004). Foi realizado um processo de composição multi-temporal das imagens escolhidas com base no uso das bandas 4 (banda do visível azul), 5 (infravermelho próximo) e 7 (SWIR) a partir da função Build Virtual Raster, disponíveis no software QuantumGIS 2.2 Valmiera. Foi feita também a composição de imagens com cores verdadeiras com base nas bandas 4, 3 e 2 (bandas TrueColor). Para o mapeamento das ravinas foram utilizadas as imagens processadas para a identificação das áreas incendiadas e o software QuantumGIS 2.2 Valmiera para o processamento das imagens. A imagem selecionada para a composição e aplicação dos índices de vegetação correspondeu à do dia 23 de Agosto de 2013, obtida dois dias depois de um grande incêndio ocorrido na área de estudo.

\section{Resultados}

O índice NBR permitiu identificar o grau de intensidade do incêndio, categorizado a partir das diferença entre R4 (banda 5) e o R7 (SWIR). Os pixéis com valores negativos obtidos a partir desta diferença (pixéis de cor vermelha) representam os sectores de maior severidade causados pelo incêndio (figura 3B). A resolução espacial do satélite LANDSAT 8 é de 30 e metros permite uma rigorosa definição das áreas incendiadas e uso e ocupação do solo (figura 3B). No entanto, a identificação de ravinas é tarefa mais difícil. Recorrendo à composição 4-3-2 (True Color) e à composição 7-5-4 (SWIR) é possível identificar as ravinas de maiores dimensões, como a ravina do Corgo, mas não permite identificar a morfologia e delimitação de forma rigorosa. 

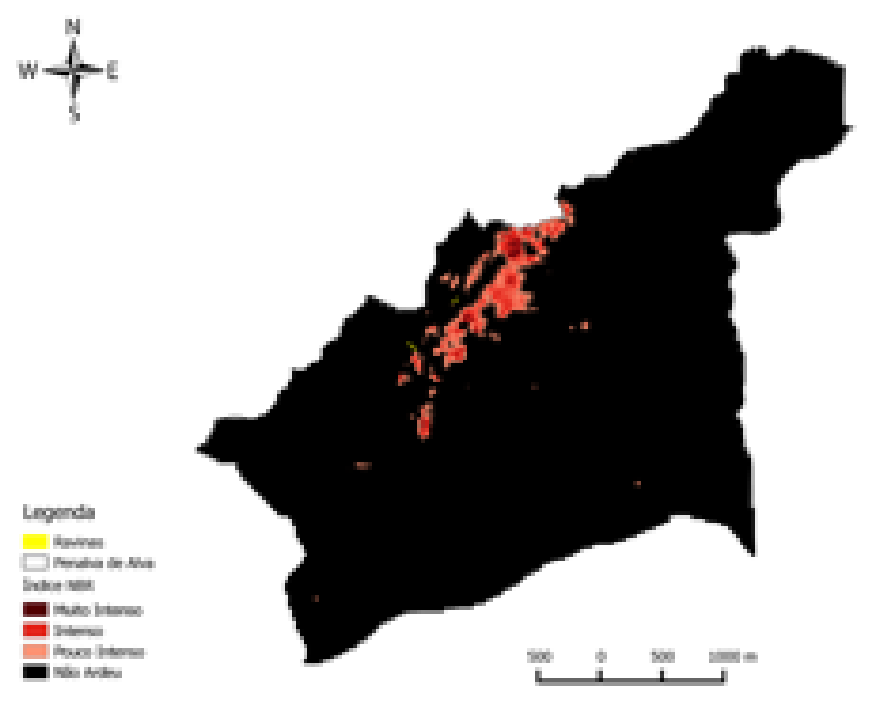

Figura 3A - Severidade do incêndio sobre a vegetação (imagem de satélite LANDSAT 8);

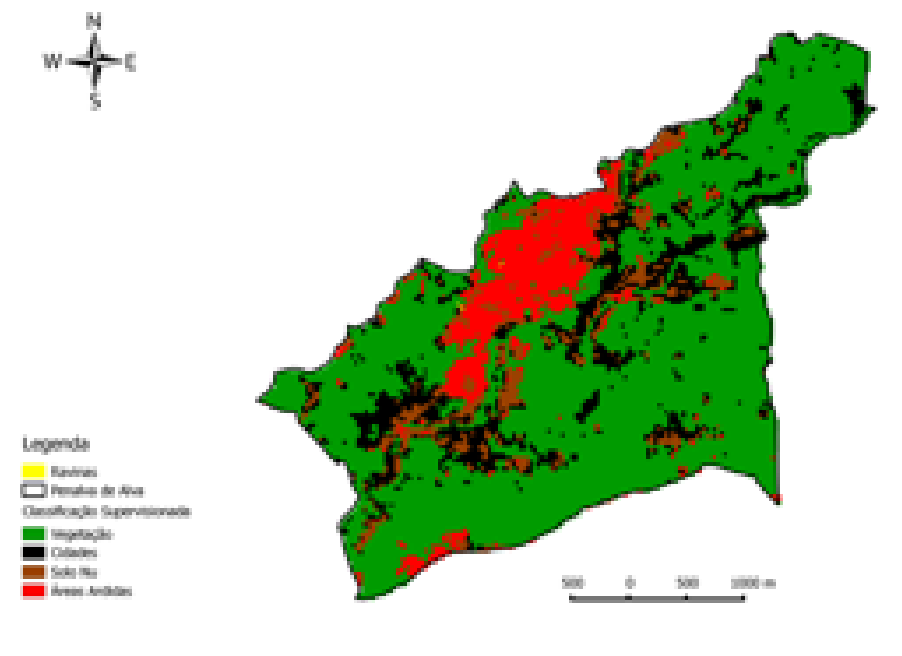

Figura 3B - Mapa do uso e ocupação do solo (imagem de satélite LANDSAT 8). 


\section{Conclusão}

A formação de ravinas depende de fatores físicos como as características climáticas, geologia, forma e tamanho da bacia hidrográfica, propriedades físicas, químicas e mineralógicas dos solos. A presença de falhas e fraturas é outro importante fator porque, ao participar diretamente na relação escorrência/infiltração, induz uma meteorização mais intensa e profunda. Este processo ganha força em rochas granitóides, como é caso da vertente onde se desenvolve a ravina do Corgo, onde a presença de um profundo manto de alteração, superior a 5 metros em vários sectores da vertente, permitiu o desenvolvimento da ravina em profundidade. Por outro lado, o uso e ocupação do solo é outra fator essencial no desenvolvimento de ravinamentos. Neste particular, a intervenção antrópica ganha força, em especial, através dos incêndios, pelo que a delimitação das áreas queimadas e a definição dos respetivos graus de severidade. Se, por um lado, urge o desenvolvimento de técnicas que permitam a cartografia da espessura das formações superficiais, por outro lado, é também muito importante a definição rigorosa das diferentes áreas de ocupação do solo. A utilização de imagens de satélite mostrou-se muito eficaz nesses desafios. No entanto, para a identificação e cartografia de ravinas, o grau de resolução das imagens trabalhadas (LANDSAT 8) não permitiu resultados satisfatórios exigindo níveis de resolução maiores.

\section{Referências bibliográficas}

Bowyer-Bower, T. \& Bryan, R. (1986) - Rill initiation: concepts and experimental evaluation on badland slopes. Z. Geomorf N.F., 60, 161-175.

DePloey, J. (1983) - Runotf and rill generation on sandy and loamy topsoils. Z. Geomorf. N.F., 46, 15-23.

Favis-Mortlock, D. (1996) - An evolutionary approach to the simulation of rill initiation and development. Proceedings of the 1st Intemational Conference on GeoComputation, Leeds, Inglaterra, 248-281.

Garcia, M. \& Chuvieco, E. (2004) - Assessmento of potential os SAC-C/MMRS imagery for mapping burned áreas in Spain. Remoting Sensing of Environment, 92, 414-423 p.

Kheir, W.; Ismail, G.; El-Nour, A.; Tawfik, T.; Hammad, D. (2007) - Assessment of the efficiency of duckweed (Lemna gibba) in wastewater treatment. Int. J. Agric. Biol. 5: 681-689.

Lourenço, L. e Nunes, A. (2014) - 0 flagelo das chamas e a recorrência de eventos hidrogeomorfológicos intensos: o exemplo da Bacia do Rio Alva (Portugal). WATERLAT-GOBACIT Network Working Papers Thematic Area Series SATAD - TA8 - Water-related Disasters - Vol. 1 N. ${ }^{\circ} 1$, p. 43-90.

Martinez-Casasnovas (2003) - A spatial information technology approach for the mapping and quantification of gully erosion, Catena, Elsevier, 50:293-308.

Martins, B.; Santos, P.; Rebelo, F. (2014) - Conhecimento e cartografia da espessura das formações superficiais na área de Pensalvos (serra do Alvão, norte de Portugal), Territorium 21, Coimbra, 115-123 p.

Slatery, M. e Bryan, R. (1992) - Hydraulic conditions for rill incition under simulate rainfall: a laborarory experiment. Earth Surface Processes and Landforms, 17, 127-146.

Rebelo, F. (2010) - Geografia física e riscos naturais, Coimbra, Imprensa da Universidade, 215 p.

Slatery, M. \& Bryan, R. (1992) - Hydraulic conditions for rill incition under simulate rainfall: a laborarory experiment. Earth Surface Processes and Landforms, 17, 127-146.

Tsimi, C., Ganas, A.; Dimoyiannis, D.; Valmis, S.; Lekkas, E. (2012) Catchment-wide estimate of single storm interrill soil erosion using an aggregate instability index: a model based on geographic information systems. Natural Hazards, Springer, 62(3). 